\title{
Specification of the Power Supply for a 6-Pole Combined Horizontal and Vertical Corrector Magnet
}

\author{
L. Emery
}

February 20, 1992

\section{Introduction}

Light Source Note LS-176[1] lists four types of corrector magnets and their power supply specifications. In order to simplify the AC operation of corrector magnets for closed orbit correction feedback, adopting a single type of corrector magnet for the whole ring is currently considered. This corrector magnet has six poles (an adaption from the ring sextupole magnet) and has coil windings producing independent horizontal and vertical bending fields. As in the other correctors, the vacuum chamber eddy current dominates the $\mathrm{AC}$ operation of the magnet which affects the voltage specification of the power supplies.

In this note, the physical requirements of the magnets will be reviewed, and the relevant magnet and power supply parameters will be reported.

A few assumptions on the local bump geometries have changed since the publication of LS176. The inner correctors of the straight section bump have been moved about $0.15 \mathrm{~m}$ inwards (towards the undulator) to conform with current vacuum chamber design. This decreases the required magnet strengths by $15 \%$ relative to those in LS-176. As of the publication date of this report, the locations of the two outboard correctors of the straight section bump are set midway between the quadrupoles Q1 and Q2. Moving these correctors closer to the Q2's will further reduce the corrector strength required. Therefore, two results are presented: one with the two outward correctors remaining at their current design locations, and one with the outward correctors moved right up against quadrupole Q2.

Also, the parameters for the bending magnet beamline bump are recalculated for a photon source placed $1 / 8$ th downstream of the entrance of the magnet. In LS-176, the photon source was assumed to be placed at the bending magnet midpoint.

\section{Physical Requirements}

The engineering specifications for the magnets and their power supplies come from the following physical requirements:

1. The local bumps must produce an orbit correction of $100 \mu \mathrm{rad}$ at $25 \mathrm{~Hz}$. The value of $100 \mu \mathrm{rad}$ is four times the required resolution of the RF BPMs. The frequency of $25 \mathrm{~Hz}$ is selected somewhat arbitrarily from the expected frequency dependence of the magnetic field attenuation through the aluminum vacuum chamber.

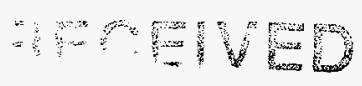

$$
f 1
$$

\section{JUL 251995}

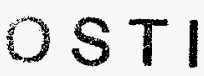




\section{DISCLAIMER}

Portions of this document may be illegible in electronic image products. Images are produced from the best available original document. 
2. Each magnet must produce a DC deflection angle of $1.2 \mathrm{mrad}$. The value of $1.2 \mathrm{mrad}$ is also selected somewhat arbitrarily. Using this value, the maximum DC local orbit bump in the straight section is $1.4 \mathrm{~mm}$ in both planes. Of course, correction magnets used for global correction can produce a much larger orbit when needed. The largest angular deflection produced by the straight section correctors is about $0.35 \mathrm{mrad}$ in both planes.

The second physical specification determines the maximum current the corrector power supply must produce. The first physical specfication determines the maximum voltage the power supply must maintain while producing a current at $25 \mathrm{~Hz}$. Here, the frequency-dependent magnet impedance is an important consideration.

\section{Magnet Data}

Table 1 gives the main parameters of the new $\mathrm{H} / \mathrm{V}$ magnet. The data in this table has been updated relative to Table 1 of LS-176, as some 3D magnet calculations are now complete. The main difference in the new data is that the magnet DC inductance calculated in $3 \mathrm{D}$ is lower than the estimated inductance published in LS-176 where an effective magnet length of twice the physical magnet length was assumed.

The necessary coil current for a deflection angle of $1.2 \mathrm{mrad}$ at $7 \mathrm{GeV}$ is calculated using TOSCA. The program GFUNET gives a lower coil current.' Since we do not know which is the more accurate program, the more conservative result of TOSCA is adopted.

The frequency dependence of magnet impedance and field attenuation (both due to the same eddy current effect) are calculated only for a $2 \mathrm{D}$ model. However, by assuming that the same frequency dependence applies to the 3D model, the 3D model magnet inductance and field attenuation simply scale from the $2 \mathrm{D}$ model. The magnet inductance and the magnitude of the magnet impedance as a function of frequency for both horizontal and vertical corrections are plotted in Figures 1 and 2.

The magnet impedance is calculated from the perturbed inductance and the extra power loss (Joule heating due to the eddy currents) in the vacuum chamber. The impedance is then used to estimate the power supply voltage requirement.

\section{Magnetic Field Attenuation Due to Eddy Currents}

The eddy current attenuation of the magnetic field through the vacuum chamber as a function of frequency is shown in Table 2 in phasor notation. The calculation is done using a 2D model. A $3 \mathrm{D}$ model was not calculated but is expected to give the same attenuation.

The attenuation depends on the vacuum chamber thickness, the shape of the vacuum chamber, and the configuration of the magnetic poles. The magnetic field always lags behind the excitation coil current, therefore the phase component appears as a negative number. The data in Table 2 is plotted in Figures 3 and 4.

\section{Power Supply Specification for Orbit Correction}

Table 3 lists various power supply parameters for a $100-\mu \mathrm{m}$ orbit correction at $25 \mathrm{~Hz}$. This table combines the effects of the attenuation of the field and of the magnet impedance perturbation. 
Table 1: New H/V Corrector Magnet Data*

\begin{tabular}{|l|c|c|}
\hline Magnet & \multicolumn{1}{|c|}{$\begin{array}{c}\text { Horizontal } \\
\text { Correction }\end{array}$} & $\begin{array}{c}\text { Vertical } \\
\text { Correction }\end{array}$ \\
\hline $\begin{array}{l}\text { Desired maximum DC deflection at } 7 \\
\text { GeV, }, \hat{\theta}_{\mathrm{DC}}(\mathrm{mrad})\end{array}$ & 1.2 & 1.2 \\
\hline Current at $\hat{\theta}_{\mathrm{DC}}, \hat{I}_{\mathrm{DC}}(\mathrm{A})^{\dagger \dagger}$ & 153 & 124 \\
\hline$\theta_{\mathrm{DC}} / I_{\mathrm{DC}}[\mu \mathrm{rad} / \mathrm{A}]$ & 7.9 & 9.7 \\
\hline DC Inductance, $L(\mathrm{mH})^{\dagger} \dagger$ & 6.0 & 7.6 \\
\hline $\begin{array}{l}\text { Unperturbed impedance as a function } \\
\text { of frequency } f^{\dagger}(\Omega)\end{array}$ & $0.068+(0.037 f) i$ & $0.099+(0.048 f) i$ \\
\hline Cutoff frequency, $f_{\text {cut }}(\mathrm{Hz})$ & 1.8 & 2.1 \\
\hline Impedance at $\mathrm{DC}, Z_{\mathrm{DC}}(\Omega)$ & 0.068 & 12.2 \\
\hline Maximum voltage for $\hat{\theta}_{\mathrm{DC}}, V_{\mathrm{DC}}(\mathrm{V})$ & 10.4 & 95 \\
\hline$\theta_{\mathrm{DC}} / V_{\mathrm{DC}}(\mu \mathrm{rad} / \mathrm{V})$ & 139 & 0.099 \\
\hline Unperturbed impedance at $25 \mathrm{~Hz}{ }^{\dagger}(\Omega)$ & $0.068+0.94 i=0.94 \angle 86^{\circ}$ & $0.099+1.20 i=1.20 \angle 85^{\circ}$ \\
\hline Impedance at $25 \mathrm{~Hz}{ }^{\dagger}(\Omega)$ & $0.139+0.51 i=0.53 \angle 75^{\circ}$ & $0.23+0.95 i=0.98 \angle 76^{\circ}$ \\
\hline
\end{tabular}

Table 2: Eddy Current Attenuation for Magnet/Vacuum Chamber System*

\begin{tabular}{|c|c|c|}
\hline $\begin{array}{c}\text { Frequency } \\
(\mathrm{Hz})\end{array}$ & $\begin{array}{c}\text { Horizontal } \\
\text { Correction }\end{array}$ & $\begin{array}{c}\text { Vertical } \\
\text { Correction }\end{array}$ \\
\hline 0.0 & 1.0 & 1.0 \\
0.2 & $0.998 \angle-5.4^{\circ}$ & $.9999 \angle-0.6^{\circ}$ \\
1 & $0.831 \angle-19^{\circ}$ & $.999 \angle-3.2^{\circ}$ \\
5 & $0.570 \angle-35^{\circ}$ & $.970 \angle-16^{\circ}$ \\
10 & $0.284 \angle-49^{\circ}$ & $.894 \angle-30^{\circ}$ \\
25 & $0.234 \angle-71^{\circ}$ & $.621 \angle-59^{\circ}$ \\
\hline
\end{tabular}

* Calculations by Larry Turner using PE2D 
Figure 1: Magnet Inductance

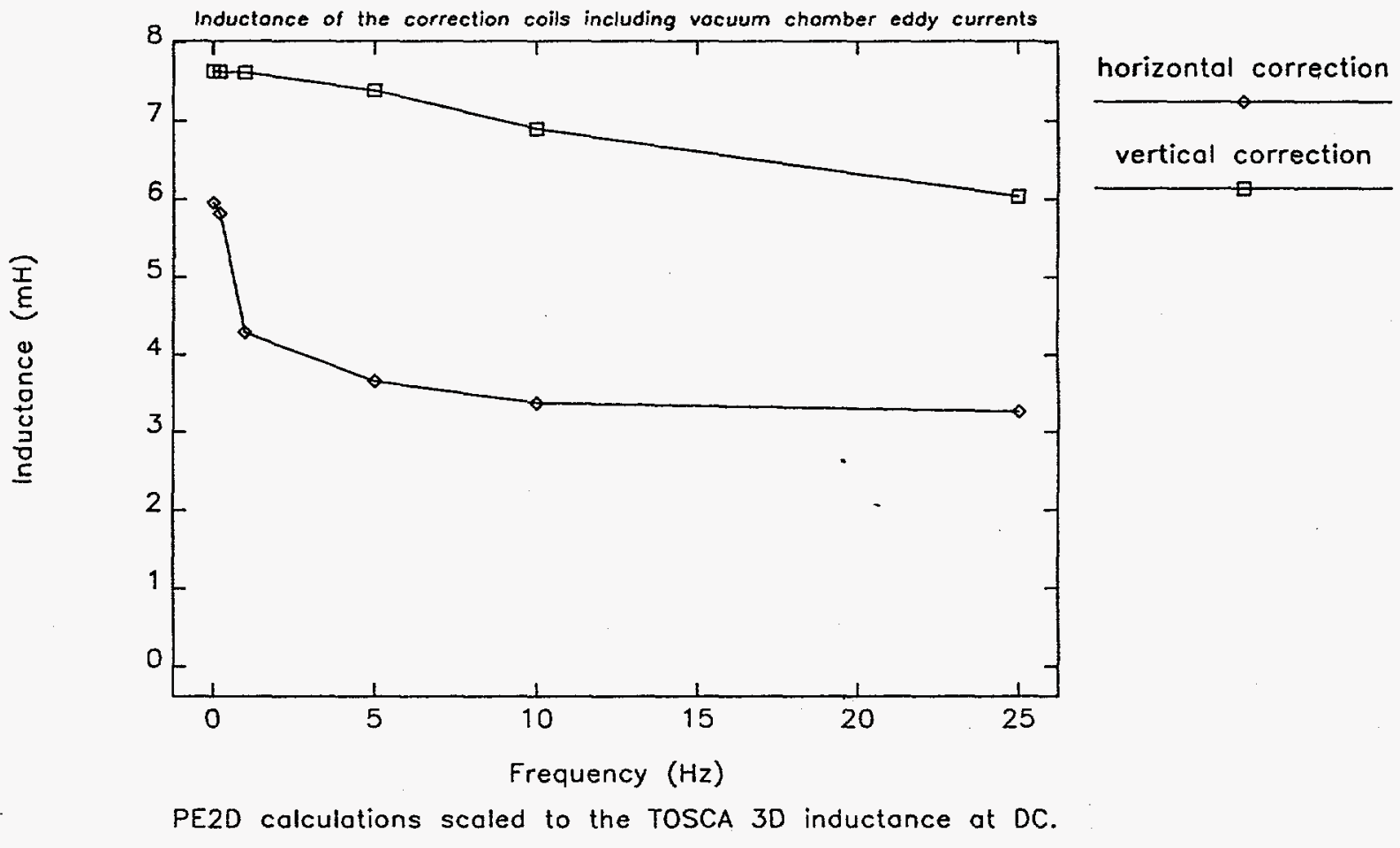

Figure 2: Magnet Impedance

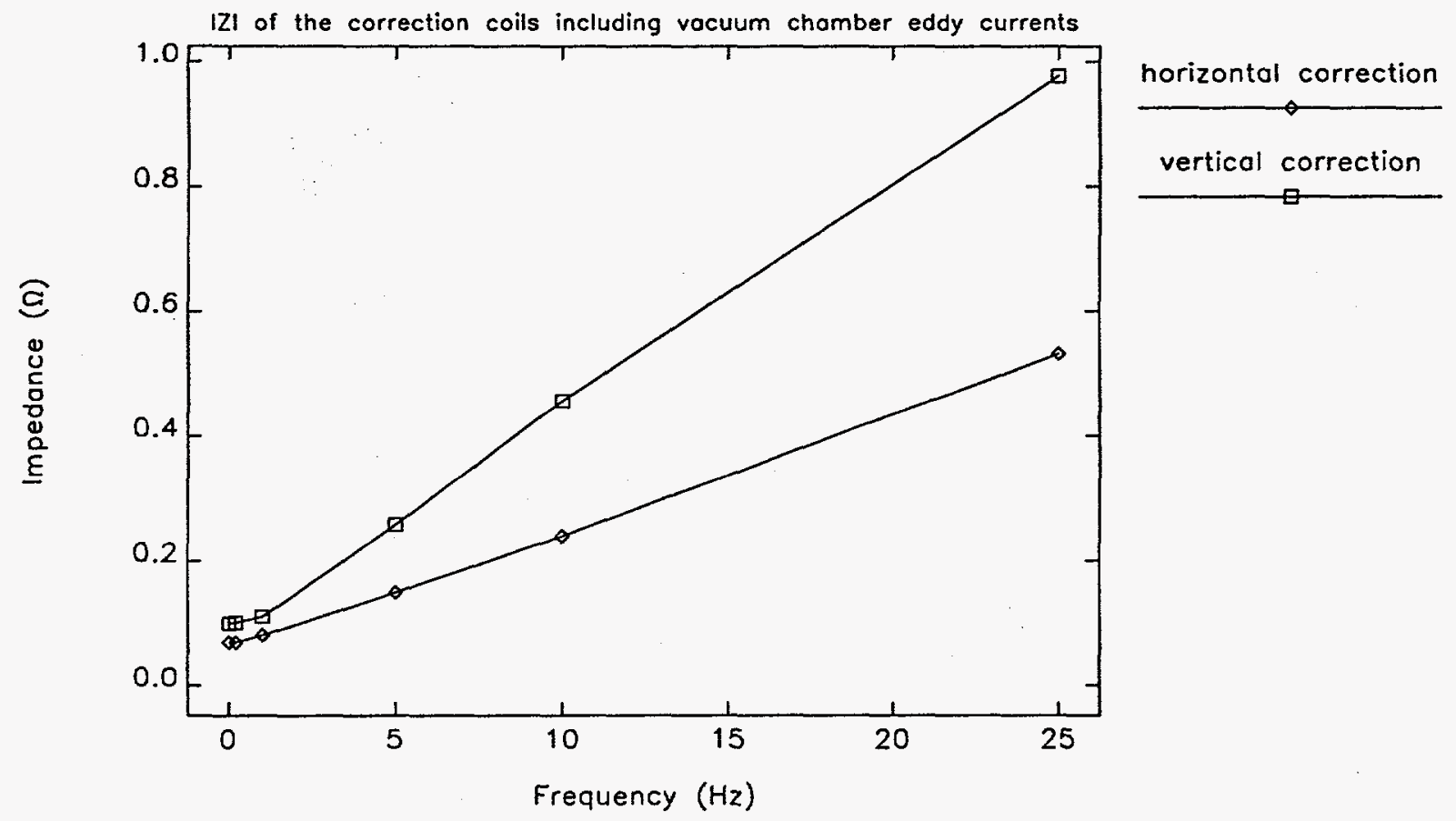

PE2O colculotions scoled to the TOSCA 30 inductonce of DC and TOSCA 30 AC-resistance of $25 \mathrm{~Hz}$. 
Figure 3: Magnetic Field Attenuation

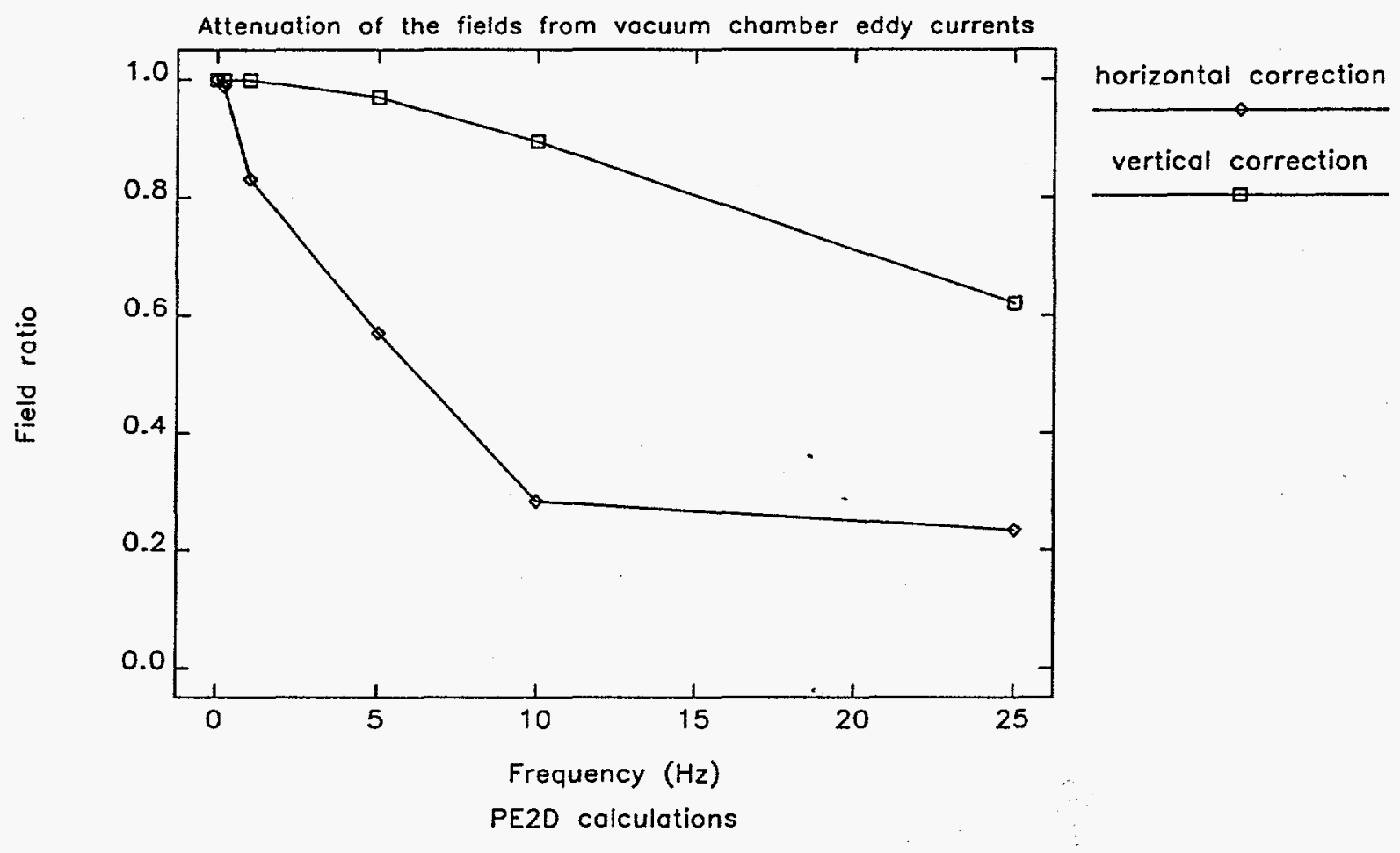

Figure 4: Magnetic Field Phase Lag

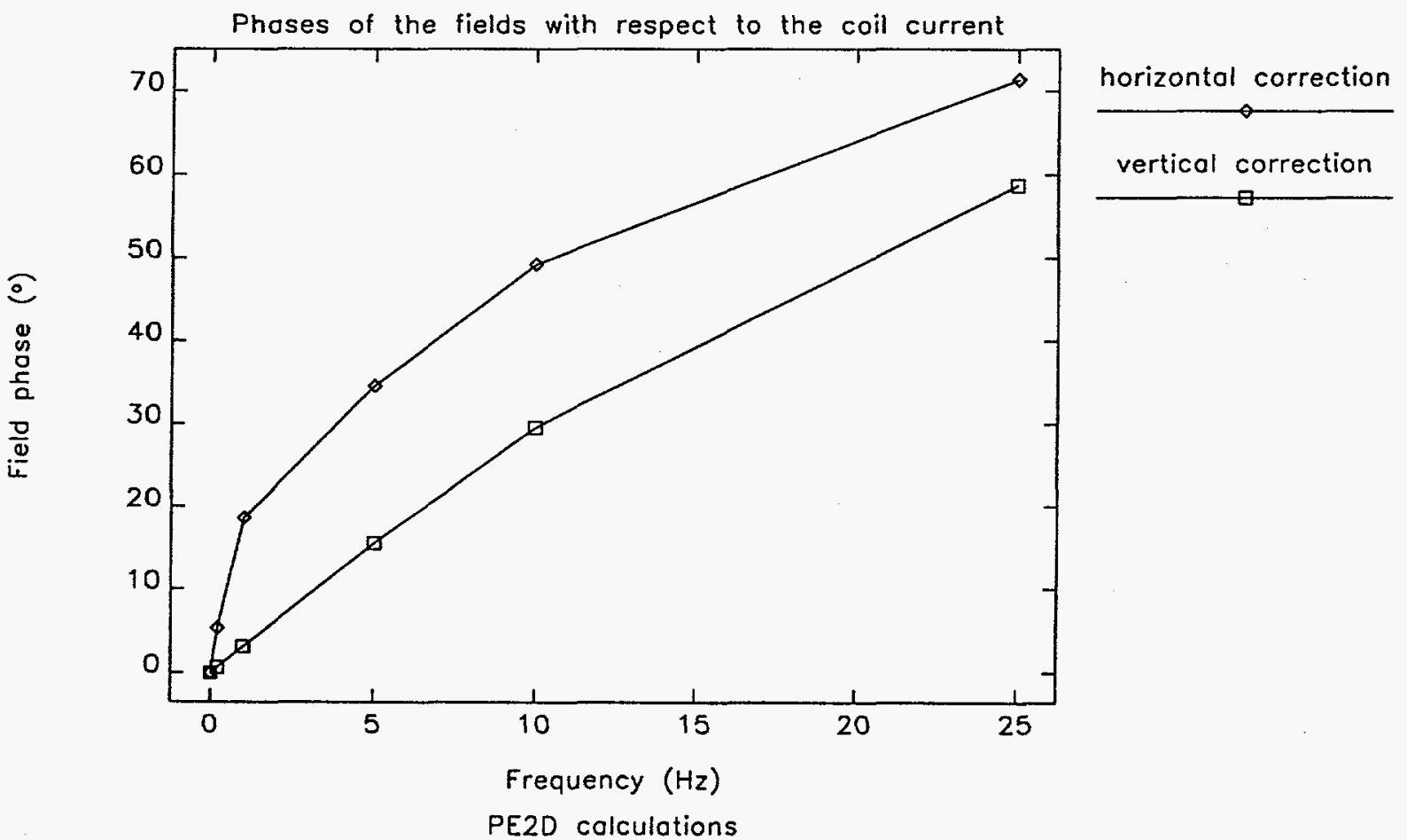


Table 3: Power supplies at $25 \mathrm{~Hz}$

\begin{tabular}{|l|c|c|}
\hline Magnet & $\begin{array}{c}\text { Horizontal } \\
\text { Correction }\end{array}$ & $\begin{array}{c}\text { Vertical } \\
\text { Correction }\end{array}$ \\
\hline Orbit motion $(\mu \mathrm{m})$ at $25 \mathrm{~Hz}$ & 100 & 100 \\
\hline $\begin{array}{l}\text { Corrector effective strength ( } \mu \mathrm{rad}) \text { at } \\
25 \mathrm{~Hz}\end{array}$ & 88 & 88 \\
\hline $\begin{array}{l}\text { Corrector current neglecting eddy cur- } \\
\text { rents }(\mu \mathrm{rad}) \text { at } 25 \mathrm{~Hz}\end{array}$ & 11.2 & 9.1 \\
\hline Vacuum chamber attenuation at $25 \mathrm{~Hz}$ & $0.234 \angle-71^{\circ}$ & $0.621 \angle-59^{\circ}$ \\
\hline Corrector current $(\mathrm{A})$ at $25 \mathrm{~Hz}$ & $48 \angle 71^{\circ}$ & $14.6 \angle 59^{\circ}$ \\
\hline Magnet impedance $(\Omega)$ at $25 \mathrm{~Hz}$ & $0.53 \angle 75^{\circ}$ & $0.98 \angle 76^{\circ}$ \\
\hline $\begin{array}{l}\text { Required Power supply voltage }(\mathrm{V}) \text { at } \\
25 \mathrm{~Hz}\end{array}$ & $25.4 \angle 146^{\circ}$ & $14.3 \angle 135^{\circ}$ \\
\hline Power supply voltage specification $(\mathrm{V})$ & not established & not established \\
\hline
\end{tabular}

The rows of the table are described as follows. The necessary beam deflection angles produced by correctors are related to the desired orbit correction by the $4 \times 2$ bump matrices as determined by the lattice optics. (See section 7.) The largest deflection angle for each plane is listed in the second row of the table.

Row 3 gives the required current for the given deflection angle neglecting eddy currents (using data from Table 1). The next row shows the attenuation due to eddy current losses in the vacuum chamber at $25 \mathrm{~Hz}$, repeated from Table 2. The phase angle of the $\mathrm{AC}$ orbit distortion is used as the phase angle reference of the attenuation. The power supply current output (row 5) is adjusted to compensate for the attenuation and the phase lag. The compensation is more pronounced for horizontal correction (vertical magnetic fields) than for vertical correction mainly because of the orientation of the vacuum chamber surface with respect to the magnetic fields. In particular, the vertical fields produced by the horizontal corrector coils are more greatly influenced by the extra material around the cooling channel.

Next, the impedance of the magnets at $25 \mathrm{~Hz}$ is repeated from Table 1 . The inductance of the magnets causes the power supply voltage for a given current to increase roughly in proportion to the signal frequency. The inductance value includes the effect of the eddy currents. The power supply voltage is simply the product of the magnet current and impedance. The power supply voltage required for a $100-\mu \mathrm{m}$ orbit correction at $25 \mathrm{~Hz}$ is listed in the second to last row of the table.

\section{Comparison with Previous Corrector Designs}

The performance of the new $\mathrm{H} / \mathrm{V}$ corrector measured in attenuation and impedance properties is comparable with that of the correctors described in the earlier note LS-176. The power supply voltage requirement for the horizontal correction coils is $25 \mathrm{~V}$. This voltage is significantly lower than the voltage listed in LS-176 for the other stand-alone horizontal dipole corrector $(43 \mathrm{~V})$. This is primarily due to the new inductance calculation of the corrector magnet in $3 \mathrm{D}$. There was also some improvement due to a slightly more efficient bump geometry. 


\section{Potential Bump Geometry Improvement}

This section is included to show how the corrector strength specification can be reduced by simply moving the outboard correctors closer to the Q2 quadrupoles. The present design locates the outboard correctors midway between quadrupoles Q1 and Q2. A more efficient design would be to move the outboard correctors outwards and the inboard correctors inwards. Unfortunately, moving the inboard correctors inwards would involve major vacuum chamber redesign. However, the outboard correctors can easily be moved closer to the Q2 quadrupoles. By the way, the present midway positions of the outboard correctors were somewhat arbitrarily set because the bump efficiency issue did not come up before.

The four corrector strengths are related to the desired orbit correction by a bump matrix. With $\mathrm{H} / \mathrm{V}$ correctors, the vertical kicks are now moved to the locations of the horizontal kicks in the new bump geometry. The four bump matrices for the corrector placement of the current design (outer correctors midway between $\mathrm{Q} 1$ and Q2) are given by the following bump equations:

1. Straight section, horizontal bump:

$$
\left(\begin{array}{l}
k_{1} \\
k_{2} \\
k_{3} \\
k_{4}
\end{array}\right)=\left(\begin{array}{rr}
0.772 \mathrm{~m}^{-1} & -2.297 \\
-0.876 \mathrm{~m}^{-1} & 3.604 \\
-0.876 \mathrm{~m}^{-1} & -3.604 \\
0.772 \mathrm{~m}^{-1} & 2.297
\end{array}\right)\left(\begin{array}{c}
\Delta x \\
\Delta x^{\prime}
\end{array}\right)
$$

where the $k$ values are the kick angles of the correctors taken in sequence along the ring segment, and $\Delta x$ and $\Delta x^{\prime}$ are the desired local orbit bump and local orbit slope, respectively.

2. Straight section, vertical bump:

$$
\left(\begin{array}{l}
k_{1} \\
k_{2} \\
k_{3} \\
k_{4}
\end{array}\right)=\left(\begin{array}{rr}
0.879 \mathrm{~m}^{-1} & -2.616 \\
-0.765 \mathrm{~m}^{-1} & 3.277 \\
-0.765 \mathrm{~m}^{-1} & -3.277 \\
0.879 \mathrm{~m}^{-1} & 2.616
\end{array}\right)\left(\begin{array}{c}
\Delta y \\
\Delta y^{\prime}
\end{array}\right)
$$

3. Bending magnet, horizontal bump:

$$
\left(\begin{array}{l}
k_{1} \\
k_{2} \\
k_{3} \\
k_{4}
\end{array}\right)=\left(\begin{array}{rr}
0.781 \mathrm{~m}^{-1} & -1.756 \\
-0.531 \mathrm{~m}^{-1} & 2.043 \\
-0.379 \mathrm{~m}^{-1} & -2.227 \\
0.392 \mathrm{~m}^{-1} & 1.267
\end{array}\right)\left(\begin{array}{c}
\Delta x \\
\Delta x^{\prime}
\end{array}\right)
$$

4. Bending magnet, vertical bump:

$$
\left(\begin{array}{l}
k_{1} \\
k_{2} \\
k_{3} \\
k_{4}
\end{array}\right)=\left(\begin{array}{rr}
0.283 \mathrm{~m}^{-1} & -0.682 \\
-0.223 \mathrm{~m}^{-1} & 1.740 \\
-0.268 \mathrm{~m}^{-1} & -1.863 \\
0.298 \mathrm{~m}^{-1} & 0.960
\end{array}\right)\left(\begin{array}{c}
\Delta y \\
\Delta y^{\prime}
\end{array}\right)
$$

For a given bump of value $\Delta x$, the largest corrector strength is given by the largest matrix element in the first column (shown in boldface). In this case a bump of $100 \mu \mathrm{m}$ for each of the four bumps above will require a maximum corrector strength of $88 \mu \mathrm{rad}, 88 \mu \mathrm{rad}, 78 \mu \mathrm{rad}$, and 30 $\mu \mathrm{rad}$, respectively.

Now if one were to move the corrector between Q1 and Q2 right next to Q2, one would get these matrices: 
1. Straight section, horizontal bump:

$$
\left(\begin{array}{l}
k_{1} \\
k_{2} \\
k_{3} \\
k_{4}
\end{array}\right)=\left(\begin{array}{rr}
0.630 \mathrm{~m}^{-1} & -1.874 \\
-0.751 \mathrm{~m}^{-1} & 3.236 \\
-0.751 \mathrm{~m}^{-1} & -3.236 \\
0.630 \mathrm{~m}^{-1} & 1.874
\end{array}\right)\left(\begin{array}{c}
\Delta x \\
\Delta x^{\prime}
\end{array}\right)
$$

2. Straight section, vertical bump:

$$
\left(\begin{array}{l}
k_{1} \\
k_{2} \\
k_{3} \\
k_{4}
\end{array}\right)=\left(\begin{array}{rr}
0.737 \mathrm{~m}^{-1} & -2.194 \\
-0.600 \mathrm{~m}^{-1} & 2.785 \\
-0.600 \mathrm{~m}^{-1} & -2.785 \\
0.737 \mathrm{~m}^{-1} & 2.194
\end{array}\right)\left(\begin{array}{c}
\Delta y \\
\Delta y^{\prime}
\end{array}\right)
$$

3. Bending magnet, horizontal bump:

$$
\left(\begin{array}{l}
k_{1} \\
k_{2} \\
k_{3} \\
k_{4}
\end{array}\right)=\left(\begin{array}{rr}
0.781 \mathrm{~m}^{-1} & -1.756 \\
-0.531 \mathrm{~m}^{-1} & 2.043 \\
-0.418 \mathrm{~m}^{-1} & -2.354 \\
0.392 \mathrm{~m}^{-1} & 1.267
\end{array}\right)\left(\begin{array}{c}
\Delta x \\
\Delta x^{\prime}
\end{array}\right)
$$

4. Bending magnet, vertical bump:

$$
\left(\begin{array}{l}
k_{1} \\
k_{2} \\
k_{3} \\
k_{4}
\end{array}\right)=\left(\begin{array}{rr}
0.283 \mathrm{~m}^{-1} & -0.682 \\
-0.223 \mathrm{~m}^{-1} & 1.740 \\
-0.294 \mathrm{~m}^{-1} & -1.948 \\
0.348 \mathrm{~m}^{-1} & 1.121
\end{array}\right)\left(\begin{array}{c}
\Delta y \\
\Delta y^{\prime}
\end{array}\right)
$$

The largest magnet strength of the straight section is reduced from $88 \mu \mathrm{rad}$ to $75 \mu \mathrm{rad}$, an improvement of $14 \%$. This will bring the required voltage of the power supply from $25 \mathrm{~V}$ down to 22 V. Slight improvements may also be possible for the bending magnet bump, but there is less room between the quadrupoles of the middle girder for corrector relocation.

To summarize, the necessary corrector power supply voltage for a $100-\mu \mathrm{rad}$ local orbit distortion in both planes is listed with cumulative assumptions.

\begin{tabular}{|l|c|}
\hline Assumptions & $\begin{array}{c}\text { Magnet voltage } \\
\text { (V) }\end{array}$ \\
\hline Previous estimate from LS-176 & 43 \\
Correctors placed at design location & 25 \\
Including outer corrector moved towards Q2 & 22 \\
\hline
\end{tabular}

\section{Acknowledgements}

I thank Glenn Decker for contributing to this note through his many comments. Larry Turner did all the magnet calculations reported in this note. Graphs by Mike Borland's mpl software.

\section{References}

[1] L. Emery and G. Decker, "Specification of APS Corrector Magnet Power Supplies from Closed Orbit Feedback Considerations," Tech. Rep. LS-176, APS, 1991. 